\title{
How Fisheries Biotechnology could Benefit Watershed-Based Rural Aquaculture?
}

\section{Muruganandam $\mathbf{M}^{*}$}

ICAR-Indian Institute of Soil and Water Conservation (ICAR-IISWC), India

*Corresponding Author: Muruganandam M, Indian Institute of Soil and Water Conservation (ICAR-IISWC), India.

Received: June 18, 2019; Published: July 03, 2019

DOI: 10.31080 /ASAG.2019.03.0555

\section{Abstract}

Fisheries sector in India has grown incredibly from the state of negligible to a potential contributor since independence progressing towards a phenomenal fish production of $12.6 \mathrm{Mt}$ (2017-18), $9 \mathrm{~kg}$ per capita fish consumption and about 1.0 per cent contribution to GDP (5.0 percent of GDP from agriculture). However, the demand-supply gap for fish in the country is ever increasing and that can only be bridged by expanding area, improving technologies and strategies of fish farming through various means such as application of biotechnological principles and promotion through Integrated Watershed Management (IWM) programmes. The IWM programmes aimed for management of natural resources and rural development promote the development of water resources, Water Harvesting Structures (WHS) and multi-sectoral farming practices including aquaculture, which enhance fisheries production. Most of the water resources developed under IWM are generally small-medium in size, seasonal in water availability and meant for multipurpose uses like flood moderation, life-saving irrigation, groundwater recharge, water source for animal drinking and fish farming.

Although fish farming in WHS has diverse and additional benefits, the associated inherent risk factors like water scarcity, reducing pond water depth over period, prevalence of clay turbidity in pond water for most periods and remoteness of the location of the water source cause operational difficulties, fish diseases, especially Epizootic Ulcerative Syndrome (EUS) and more production losses as compared to any other fish culture systems. These inherent risk factors could be solved by solutions from molecular biology and aquacultural biotechnology, which may include production of specific disease-free fish or prawn seedlings, early diagnosis of outbreak using modern techniques like Polymerase Chain Reaction (PCR) and other immuno-diagnostic approaches. As widely known, aquaculture biotechnology holds immense scope for converting new discoveries made in fish biology into industrial and aquacultural applications through various tools and techniques such as recombinant-DNA (r-DNA), embryo transfer technology, chromosomal engineering, hybridoma technology, production of monoclonal antibodies and gene probe (DNA probe) for germplasm development or conservation, production of transgenic fish, diagnosis or treatment of major diseases and recycling of wastes. However, a little has been done on these fronts to benefit aquaculture despite vast potential in the country. A brief account on genetical and biotechnological applications for advancement of fisheries with special reference to the context of IWM is presented here.

Keywords: Fisheries; Biotechnology; Watershed Pond, Integrated Watershed Management (IWM)

\section{Introduction}

The word "biotechnology" is variously defined to mean wide range of activities that processes biological agents for goods and services using scientific and engineering principles. The Convention on Biological Diversity (CBD) defines biotechnology as any technological application that uses biological systems, living organisms or derivatives thereof to make or modify products or processes for specific use. The traditional or conventional biotechnology aims to improve existing genomes of organisms and modern biotechnology strikes to alter genome for intended benefits. The comparison of antiquity and modernity of developments brings forth higher-level advancements in biotechnology, and today it offers valuable applications. Principles of biotechnology have thrown enormous light on the improvement and utilities of natural resources. Sometimes, aquaculture as such is considered to be within the principles and practices of biotechnology. Today, aquaculture of various species immensely contributes to national agenda of increasing food production, poverty alleviation, eradication of malnutrition and improving employment potential. Biotechnological applications for fisheries development are increasingly re- lied on genetic manipulation, hormonal engineering, immunology- based 
disease diagnosis or control and economic culture of various aquatic organisms and post-harvest techniques [1,2]. However, real bio-technological studies on aquaculture species are relatively inadequate as compared to other agricultural sciences. In agriculture and animal husbandry, traditional selection and field level hybridization for possible vigor by mixing varieties or strains while sowing or animal servicing is executed even by traditional farmers [3], which is very remote for fish farming except in certain pockets of West Bengal. The situation warrants bio-technological research in areas of scientific aquaculture, genetic improvement in fish and other aquatic organisms like shrimps, selective breeding, management of farming inputs and diseases, fish processing, extraction of aquatic biomedicines or useful toxins and environmental or pollution management. Also, in taxonomic or genetic inventorization of aquatic organisms and biodiversity conservation efforts, biotechnological and genetic tools are found potential uses, especially under the modern regime of increasing importance for Intellectual Property Rights (IPR) and increasing loss of biodiversity due to various pressures. Application of genetics and biotechnology could play a major role to accelerate aquacultural productivity and overall output from watershed-based fish culture. Potential of biotechnological tools and techniques with introspection on its influence to enhance watershed-based fisheries development is made.

\section{Relevance of biotechnology in watershed-based aquaculture}

In the arena of increasing emphasis over IWM from governmental, non-governmental, private and public interests create number of small WHS or dams for productive uses including fish farming [4]. Fish culture in watershed management programmes is at present a low-input and low-yielding endeavor due to existing interfaces between watershed management principles and fish farming necessities [5]. Availability of water for limited period up to 3-6 months during monsoon and post-monsoon (July-Nov.) and inadequate design features considered or accommodated in WHS constraint successful fish farming in WHS [6,7]. Scope for enhancing fish productivity in watershed ponds through environmental manipulation like optimum use of fertilizers, feeds, and improved or controlled water quality management is minimum since the whole or maximum part of culture period depends on scarce rainfall-runoff which is very much limited in terms of quantity and duration of availability, i.e., uncertain in availability and lasts for short span of duration, besides being subjected for competitive use from other sectors of agriculture. But, the biotechnological tools offer potential to improve fish yield particularly by employing genetically modified or improved stocks since transgenics in fisheries has immense potential to sustain future fish production and conservation of fish resources [8]. Increased resistance of fish to cold temperatures and prevalent disease causing agents may be possible through the tools of genetic advancements like production of transgenic fishes. Promising progress on identification and the potential of cold-tolerant genes or factors in coldwater fish species has been reported, which would find application in development of cold-tolerant species [9].
If fast growing and cold tolerant species or strains are developed, majority of seasonal watershed ponds and Himalayan water resources could effectively be utilized for fish production. However, as on today, very few genetically superior aquatic species are available for aquaculture and unfortunately, biotechnological development could not percolate down to the programmes of watershed management to the required level. At this juncture, biotechnology can benefit general fisheries and aquaculture development if the critical biotechnological end-results that would benefit watershedbased aquaculture are internalized as summarized below.

1. Fast growing fish species that reach marketable size in a reasonably short duration would be of great help for watershed based fish farming since most watershed ponds or WHS hold water for short period. Identification and incorporation of genes that increase production of natural fish growth factors and natural defence compounds in preferred fish species would enhance fisheries yield manifolds.

2. Fish species that can bear over-crowding or higher density could be useful to watershed ponds, since water volume in watershed ponds gradually reduces to minimum over time from monsoon to post monsoon causing fish biomass densest and stressed at later stage of culture.

3. Cold tolerant strains could help exploitation of majority of mountain and Himalayan watersheds where number of watershed development programmes and WHS are being undertaken. Disease resistant strains especially for EUS would be more successful and profitable as fish farming in watershed ponds suffers due to diseases relatively more than any other systems $[4,10]$.

4. Maintenance of self-sustaining feeding regime based on natural fish foods (zooplanktons, phytoplanktons, benthos etc.) using general biological or ecological feeding principles and through appropriate stocking of seeds, recycling of agricultural wastes and improved farming techniques such as introduction of bio-films or microfilm techniques, biofloc technology etc. would improve economics of fish farming since feed accounts for about $60 \%$ of input costs and feeding potential in watershed ponds is minimum due to various reasons.

5. Development of effective transport agents (sedatives or metabolism reducers) for effective transfer of fishes and fish seeds while stocking or live fish marketing would improve success of fish farming in WHS or watershed ponds. Because, often watershed ponds are located in far off places amidst forest or in remote location that require extensive transport. Extraction of sedatives from natural anaesthetizers like timru plant (Zanthoxylum armatum) would serve the purpose. 
6. Cost-effective and user (farmers) friendly disease diagnostic kits or treatment package with easy endpoint identification execution at field level for at least common diseases may be helpful for watershed based aquaculture since watershed ponds are often subjected to vagaries of pressures from nature and possess high risks for occurrence of fish diseases.
Available literatures suggest that various biotechnological tools and techniques as briefed in Box 1 can achieve most of the above potential areas. Production of genetically improved and domesticated transgenic aquatic organisms like fish, prawn and mollusks through r-DNA, embryo transfer technology, and chromosomal engineering such as polyploidization and hybridization involving

I. Induction and control of maturation, spawning and breeding (inbreeding, selective and cross breeding (hybridization) to achieve domestication, increase survival rate and productivity. Majority of fish species including Indian Major Carps (IMC) and shrimps are bred through hormonal manipulation. With systematic and Marker Assisted Selective breeding (MAS), economically and environment-friendly species or strains could be produced.

II. Introduction of sex control (gynogenesis and androgenesis for all female or male) in some species like Tilapia spp. Sex inversion in protoandrous species like sea bass and protogynous species like groupers.

III. Genetic improvement through conventional quantitative genetic techniques like selection and induced breeding, production of ploidy (e.g. triploides, tetraploids) and transgenic species through modern tools like r-DNA technology and chromosomal engineering involving temperatures, hydrostatic pressure or chemical shocks, undifferentiated or totipotent embryonic stem cell (ESC) technology and gene transfer for cold tolerance, growth promotion, disease resistance, large size or biomass production, enhanced protein content, improved feed conversion efficiency (FCE) and other economic traits.

IV. Prophylactic health management and immunological potential for disease diagnosis (molecular and immuno-diagnostic) kits or methods like direct florescent antibody test (D-FAT), Enzyme Linked Immuno Sorbant Assay (ELISA), DNA-based diagnostics (DNA probes, DNA vaccines) and Polymerase Chain Reaction (PCR). Management by probiotics, vaccines (chemically or heat inactivated whole cells, inactivated soluble cell extracts (Toxoids), cell-lysat, attenuated live vaccines), immunostimulants, gene therapy etc.

V. Programmed cell death (apoptosis) in health and disease management.

VI. Cell and tissue culture for in vitro viral culture, pearl culture, health and diagnostic studies or management.

VII. Conservation of germplasm (cryo-preservation of gametes and embryos) and molecular taxonomic or genetic inventorisation.

VIII. Aqua feed production - nutrient enrichment of feed ingredients or raw materials (fermentation, reduction of anti-nutrients and crude fiber levels), feed or waste improvement by Solid-State Fermentation (SSF), bio encapsulation of live foods, production of enzymes (a-amylase, b-amylase cellulase, phytase etc.), amino acids (I-lysine, threonine etc.), vitamins (B 2 , B12, biotin etc.), organic acids (lactic acids etc.), flavors, growth promoters, essential fatty acids etc., non-conventional feed compositions or production (fermentation and composting of biologically degradable wastes, single cell protein (SCP, e.g. Spirulina spp.) production, culture of phytoplankton, zooplankton and benthos such as Chironomus larvae, Tubifex, Moina, Daphnia, rotifer, micro-algae, etc.)

IX. Production of bioactive or pharmaceutical compounds and non-primary or secondary metabolites (organic compounds produced by microbes, sponges, seaweeds and other aquatic organisms) for human or animal use and from terrestrial biomass for aquatic organisms (as feed ingredients for proteins, vitamins, amino acid supplements, feed additives for color, flavor, taste etc. and as immunostimulants, toxicants or stupefecants, probiotics, preventive or curative formulated products).

X. Harvest and post-harvest processing of fish and fishery products (fermentation, salting and drying to produce fish sauce, fermented fish, fish paste, fishmeal, biological (fish) silage, fertilizer etc. for various purposes) involving microbiology and biochemical interventions.

XI. Environmental (aquatic) bio-remediation: Sewage or waste water remediation or purification by microbes through bioconversion for productive uses like fish farming is one of the microbial techniques. Fish farming as such would improve water quality by reducing organic wastes.

XII. Fish as model for various aspects including genetic studies, cell line propagation and environmental monitoring. Genetic variations due to environmental pollution are monitored through fish micronucleus test, chromosome aberration, DNA:RNA ratio etc.

XIII. Improved fish and shrimp culture techniques such as use of biofilm or biofloc technology in ponds to enhance natural food organism through enhancing surface area of pond.

Box 1: Biotechnological interventions in aquaculture include various processes, products and techniques. 
manipulation of Growth Hormone (GH) genes for promoted growth, increased nutritional value, flavor and aroma, disease or stress resistance, besides, hormonal control of sex and growth are some of main frontiers of biotechnology that can transform aquaculture potential in to a great reality. Besides, feeding application of bioenergetic techniques and optimal feed regime following enzyme and protein engineering, fermentation, improvement of Feed Conversion Ratio and Efficiency (FCR and FCE), development of new diagnostic agents or methods like vaccines, monoclonal antibodies and gene probe (DNA probe) using tissue or cell culture, protoplast fusion, hybridoma technology to monitor pathogens or diseases, production of improved strains of probiotics, and other optimized strategies of scientific and engineering principles of holistic farming activities hold promise for radical development in aquaculture [11-14].

\section{Conclusion}

Although biotechnology holds immense hope for advancement of fisheries and human development, most of the specified techniques and benefits are yet to be exploited or commercialized successfully that requires further studies and emphasis to advance our understanding on unabridged knowledge on the subject. If modern biotechnological tools and techniques that are mostly laboratoryoriented and adopted from veterinary and human medicine are suitably refined and taken to field level, a quantum jump in fish production would be achieved.

\section{Bibliography}

1. CMFRI. "Course manual for Winter School on recent advances in Mariculture genetics and biotechnology held during 4-24th Nov. 2003". CMFRI, ICAR, Kochi-682 041. 37 chapters (2003).

2. Dunham RA. "Aquaculture and fisheries biotechnology". Genetic approaches CABI. (2011): 504.

3. Suraj Bhan. "Experience of indigenous technologies". Journal of Soil and Water Conservation 5.4 (2006): 46-58.

4. Muruganandam M. "Aquaculture in water harvesting structures". In: G. P. Juyal and V. N. Sharda (eds). Water harvesting structures and bioengineering measures for drainage line treatments in a watershed. Agrotech Publishing Academy, Udaipur-313 001. (2010): 319-331.

5. Muruganandam M., et al. "Interfaces between Composite Carp Culture and Watershed Management in Northwestern Foothill Himalayas". In: Hanifa, M. A. (ed). Aquatic resources and aquaculture. Dominant Publishers and Distributors Pvt Ltd, New Delhi (2011): 285-300.
6. Muruganandam M. "Aquaculture Potential for Integrated Watershed Development in Shiwalik and North Western Himalayas: Problems and Prospects". Indian Journal of Soil Conservation 27.3 (1999): 234-242.

7. Muruganandam M. "Studies on Watershed-Oriented Fisheries Development in Lower and Mid-Himalayas". Thesis submitted to H. N. B. Garhwal University, Central University, Srinagar, Uttarakhand for the award of Doctor of Philosophy (2009): 243.

8. Ayyappan S and A Gopalakrishnan. "Transgenics in fisheries: perspectives, priorities and preparedness for India". Indian Journal of Fisheries 53.2 (2006): 127-152.

9. DCFR. Directorate on Coldwater Fisheries Research (DCFR), ICAR, Bhimtal Annual Report 2010-11 (2011): 6 and 56.

10. Muruganandam M., et al. "Occurrence and management of Epizootic Ulcerative Syndrome (EUS) in rainfed fishponds to sustain fish production". In: Abstract proceedings of the International symposium on sustainability of fish production systems and appropriate technologies for utilization (SustainFish 2005). CUSAT, Cochin, India (2005): 181.

11. Bols NC and L E J Lee. "Technology and uses of cell cultures from the tissues and organs of bony fishes". Cytology 6 (1991):163-187.

12. Heppell J., et al. "Development of DNA vaccines for aquaculture". In: Abstract proceedings of 4th International Marine Biological Conference, IMBC, 97, Sorrento, Paestum, Otranto, Pugnochniso, Italy (1997).

13. Meagre A. Cytokines. Open University Press, Buckingham, UK (1990).

14. Sin T Y T. "Transgenic fish". Reviews in Fish Biology and Fisheries 7 (1997): 417-441.

Volume 3 Issue 8 August 2019 (C) All rights are reserved by Muruganandam $\mathbf{M}$. 